\title{
Meta-Analysis of the Diagnostic Accuracy of Primary Bone and Soft Tissue Sarcomas by ${ }^{18}$ F-FDG-PET
}

\author{
Manaf H. Younis ${ }^{a}$ d Hasan A. Abu-Hijleh ${ }^{b}$ Osama O. Aldahamsheh ${ }^{b}$ \\ Abdulrahman Abualruz ${ }^{c}$ Lukman Thalib ${ }^{d}$ \\ a Department of Orthopedic Surgery, Jackson Memorial Hospital, University of Miami, Miami, FL, USA; \\ ${ }^{b}$ Department of Orthopedic Surgery, Hamad General Hospital, Doha, Qatar; ' Department of Radiology, Wake

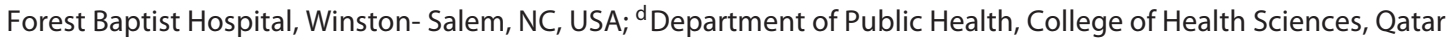 \\ University, Doha, Qatar
}

\section{Highlights of the Study}

- Some sarcomas present substantial diagnostic challenges that demand accurate diagnostic modalities.

- We performed a meta-analysis of available evidence and found the pooled sensitivity and specificity of FDG-PET combined with CT for the detection of sarcomas to be 89.2 and $76.3 \%$, respectively, i.e., higher than those of FDG-PET alone.

- FDG-PET can efficiently differentiate between benign and malignant tumors, with a mean standard uptake value of maximally 2.52 units in benign and 6.81 units in malignant tumors with $89.2 \%$ sensitivity and $75.1 \%$ specificity.

\section{Keywords}

Positron emission tomography · PET · Sarcoma •

Meta-Analysis

\begin{abstract}
Objectives: The goal of this meta-analysis was to assess the use of FDG-PET in the diagnosis of primary bone and soft tissue sarcomas. Subjects and Methods: Several databases, including PubMed, Embase, Cochrane Library, and Web of Science, were searched. In addition to sensitivity and specificity, the diagnostic accuracy region for detecting and grading sarcomas were pooled using bivariate and hierarchical summary receiver-operating characteristic (HSROC) models. Subgroup analysis included pooling soft tissue and bone sar-
\end{abstract}

karger@karger.com www.karger.com/mpp

Karger $\stackrel{\text { ' }}{5}$
(C) 2019 The Author(s)

Published by S. Karger AG, Basel

Karge

Open access

This is an Open Access article licensed under the Creative Commons Attribution-NonCommercial-4.0 International License (CC BY-NC) (http://www.karger.com/Services/OpenAccessLicense), applicable to the online version of the article only. Usage and distribution for commercial purposes requires written permission. comas separately, and sensitivity analysis included highquality studies. The quality of eligible studies was assessed using QUADAS-2. Results: Of the 1,258 papers screened, 21 studies satisfied the inclusion criteria. The pooled sensitivity and specificity of FDG-PET combined with CT for the detection of sarcomas were 89.2 and $76.3 \%$, respectively. These diagnostic accuracy measures were higher when combined with CT than those of PDG-PET alone. Diagnostic accuracy for bone and soft tissue lesions were comparable but slightly better for soft tissue tumors. Pooling only the high-quality studies with low risk of bias yielded a sensitivity of $88.5 \%$ and specificity reduced to $65.6 \%$. There was no evidence for publication bias, but significant heterogeneity among the studies was apparent. This study also showed that FDG-PET can efficiently differentiate between benign and malignant tu-
Prof. Lukman Thalib

College of Health Sciences, Health Cluster, Qatar University University Street, Al Tarfa

Doha 2713 (Qatar)

Lthalib@qu.edu.qa 
mors, with a mean standard uptake value of maximally 2.52 units in benign and 6.81 units in malignant tumors $(89.2 \%$ sensitivity and $75.1 \%$ specificity). Conclusion: Our findings indicate FDG-PET can efficiently differentiate between benign and malignant bone and soft tissue tumors. We also found that FDG-PET improves accuracy in diagnosing soft tissue sarcomas when combined with CT.

(C) 2019 The Author(s)

Published by S. Karger AG, Basel

\section{Introduction}

Bone sarcomas account for less than $0.2 \%$ of malignancies, whereas soft tissue sarcomas constitute less than $1 \%$ of all cancers [1]. The radiological tools used in the diagnosis and staging of musculoskeletal sarcomas encounter several challenges as sarcomas form a substantial diagnostic dilemma that demands new modalities to provide better evaluation. Positron emission tomography (PET), a noninvasive imaging technique that detects $\gamma$-rays emitted from isotopes, has the potential to increase diagnostic accuracy. In particular, the uptake of fluorine-18 deoxyglucose ( $\left.{ }^{18} \mathrm{~F}-\mathrm{FDG}\right)$ is used to detect the increased metabolic rate of glucose by tumorous cells [2]. ${ }^{18} \mathrm{~F}-\mathrm{FDG}$-PET allows visualization of the tumors as it reflects the metabolic rate of metabolically active tumors in human tissues, and tumors of higher grade are more metabolically active than those of lower grade. Although FDG uptake cannot differentiate between the histological tumor subtypes, it was sufficiently accurate to differentiate low- from high-grade sarcomas given different standard uptake values (SUV). However, differentiating between benign tumors and low-grade sarcomas was reported to be difficult $[3,4]$. Due to the low incidence of bone and soft tissue sarcoma, and the high costs of PET imaging, most of the published studies had only small numbers of patients; therefore, the level of evidence obtained from these smaller studies were mostly underpowered. Because of that, it was important to pool the effect measures to provide higher-quality evidence that can be used to build guidelines for the diagnosis and management of bone and soft tissue sarcomas.

The aim of this study was to provide an updated review of the published evidence on the level of accuracy of PET in the diagnosis and grading of primary bone and soft tissue sarcomas. Furthermore, this study aims to quantify the added diagnostic accuracy in combing CT with PET.

\section{Subjects and Methods}

This study utilizes a meta-analytical approach to synthesize evidence from observational diagnostic studies. The PRISMA (Preferred Reporting Items for Systematic Reviews and MetaAnalyses) statement [5] and the checklist for Meta-Analyses of Observational Studies (MOOSE) [6] guided the reporting of this study. This review is registered with the International Prospective Register of Systematic Reviews (PROSPERO CRD42018081904).

\section{Search Strategy}

A comprehensive search was performed in Medline, Cochrane Central including Cochrane Central Register of Controlled Trials, Embase, and Web of Science, from January 1, 1990, through December 1, 2017, to retrieve all published studies assessing the role of FDG-PET in the detection and grading of musculoskeletal tumors. The search was limited to human subjects and English language publications. A manual search using reference lists of original research and reviews was also carried out. The search terms used were PET OR positron emission tomography) AND (bone tumor OR osseous sarcoma OR sarcoma) as words in the title or abstract.

\section{Inclusion and Exclusion Criteria}

Studies that used FDG-PET and pathological confirmation of bone or soft tissue tumors were included. Case reports, reviews, editorials, or animal studies, as well as studies using multiple imaging modalities in combination without a clear way to discern the data evaluating each modality separately were excluded. Reports of musculoskeletal tumors in combination with other tumors, in a way data could not be extracted separately, were also excluded.

\section{Data Extraction}

Data were extracted independently by 2 reviewers. Adjudication was done by a third author.

\section{Risk of Bias Assessment}

Risk of bias was independently assessed by 2 reviewers using Quality Assessment of Diagnosis Accuracy Studies (QUADAS-2) [7], a validated tool for assessing diagnostic studies.

\section{Data Synthesis}

Meta-analyses were used to pool the accuracy measures of FDG-PET in detecting and grading sarcomas. This included analysis of different FDG-PET interpretation methods and combined FDG-PET and CT scan. Accuracy estimates were obtained using both the bivariate and the hierarchical summary receiver-operating characteristic (HSROC) models. Meta-analyses were conducted using comprehensive meta-analysis (CMA, version 3; Biostat, Englewood, NJ, USA), Meta-Disc (version 1.4; Complutense University of Madrid, Spain), and Metandi modules of Stata (release 15; StataCorp LLC, College Station, TX, USA).

In addition to the visual inspection of the forest plots, the bivariate and hierarchical models were used to quantify the amount of heterogeneity. The area of the prediction ellipse allows interpretation of the between-study heterogeneity as a proportion that is naturally bounded in the ROC space area. To assess the publication bias, Hunter's funnel plot was used. 
Fig. 1. Flow diagram of studies included in the meta-analysis.

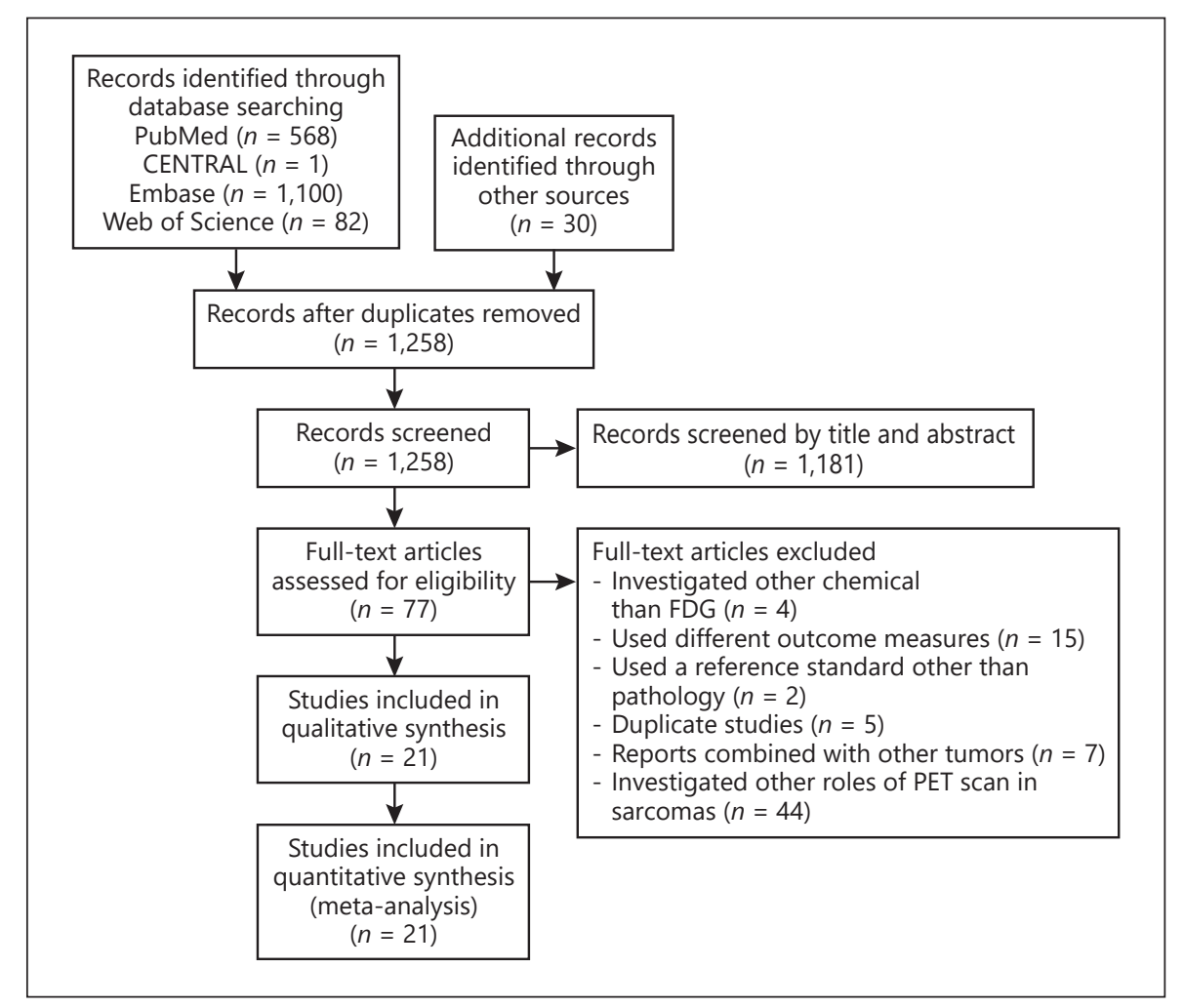

\section{Results}

Of the 1,258 articles screened, 21 were selected for the final analysis (Fig. 1). Of these 21 studies, 17 evaluated bone and soft tissue sarcomas using FDG-PET, whereas 5 used PET/CT either alone or in combination with dedicated FDG-PET. Nine studies were on soft tissue sarcomas only, and 7 on bone sarcomas alone. The remaining 5 studies evaluated both sarcomas; however, data on bone and soft tissue tumors could not be separated.

The meta-analysis included a total of 1,198 patients and 1,205 lesions. Sample sizes of the studies ranged from 11 to 202 . Patient age ranged from 1 to 89 years, and 55\% were males (Table 1). The soft tissue sarcomas were predominantly located in the extremities, while the bone and mixed sarcomas were also located in the trunk. Except for 4 studies, all studies had histopathological examination as the reference test.

In terms of the quality of the studies, the majority of the studies had relatively moderate to high quality (Table 2). The exclusion criteria were described in only $39 \%$ of the studies. Most studies used valid reference tests, yet it was unclear if the reference standard was performed blindly from the index test. Most studies described the index test FDG-PET procedures in sufficient details, yet a cutoff was prespecified in only 2 studies. In $24 \%$ of the studies, it was not clear whether the index test was interpreted independently of the reference test or not. In 4 studies, part of the study subjects received a reference standard other than the histopathology. The time interval between the index test and the reference standard was unclear in 14 studies. In 4 studies, not all patients had undergone the reference standard tests, with the proportion ranging from 8 [8] to $45 \%$ [9].

Twenty-one studies provided sufficient data for calculation of the sensitivity and specificity for the detection and grading of sarcoma. The overall pooled sensitivity was $89.2 \%$ (95\% CI: 82.3-93.7\%), and pooled specificity was $75.1 \%$ (95\% CI: 69.8-81.9\%) (Fig. 2). The area under the summary ROC curve was $87.5 \%$ (Fig. 3). We found sensitivity, specificity, and AUC of bone sarcomas to be 87.2\% (95\% CI: 78.1-94.8\%), 71.4\% (95\% CI: 58.3-82.6\%), and $86.9 \%$, respectively. Likewise, for soft tissue sarcomas, sensitivity was $89.0 \%$ (95\% CI: 79.4-95.2\%), and specificity was $72.1 \%$ (95\% CI: 60.9-85.9\%) with an AUC of $90.2 \%$.

PET scans were interpreted using the semiquantitative method (SUV) in 19 studies, from which we extracted the 
Table 1. Characteristics of the 21 studies included in this meta-analysis

\begin{tabular}{|c|c|c|c|c|c|c|c|c|}
\hline $\begin{array}{l}\text { Ref. } \\
\text { No. }\end{array}$ & Country & Design & $\begin{array}{l}\text { Pat., } \\
n\end{array}$ & $\begin{array}{l}\text { Mean age } \\
\text { (range), years }\end{array}$ & $\begin{array}{l}\text { Males/ } \\
\text { females }\end{array}$ & $\begin{array}{l}\text { Soft tissue, bone, } \\
\text { or mixed }\end{array}$ & Location & $\begin{array}{l}\text { Histopathol. } \\
\text { confirmed, } n\end{array}$ \\
\hline 10 & USA & prospective & 25 & $49(18-86)$ & - & $\begin{array}{l}\text { mixed: } \mathrm{ST}=16 \\
\mathrm{~B}=9\end{array}$ & unclear & 25 \\
\hline 11 & USA & prospective & 20 & $55(5-87)$ & $12 / 8$ & B & unclear & 20 \\
\hline 12 & Netherlands & prospective & 22 & $50(18-82)$ & $13 / 9$ & ST & $\mathrm{LL}=20, \mathrm{UL}=2$ & 22 \\
\hline 14 & UK & retrospective & 29 & $50(18-76)$ & $14 / 15$ & ST & unclear & 29 \\
\hline 15 & Germany & prospective & 102 & $49(1-89)$ & $55 / 47$ & ST & $\begin{array}{l}\mathrm{LL}=49, \mathrm{UL}=25 \\
\text { trunk }=28\end{array}$ & 102 \\
\hline 4 & Japan & prospective & 11 & $44(12-78)$ & $4 / 7$ & B (chondrosarcoma) & $\begin{array}{l}\mathrm{LL}=5, \mathrm{UL}=3, \\
\text { trunk }=3\end{array}$ & 11 \\
\hline 17 & UK & prospective & 18 & $23.5(12-62)$ & $8 / 10$ & $\begin{array}{l}\text { ST (malig. } \\
\text { neurofibroma) }\end{array}$ & $\begin{array}{l}\mathrm{LL}=13, \mathrm{UL}=3, \\
\text { trunk }=7\end{array}$ & 12 \\
\hline 18 & Germany & prospective & 19 & $54(16-78)$ & - & ST & unclear & 19 \\
\hline 19 & Japan & prospective & 52 & $45.3(12-77)$ & $26 / 29$ & $\begin{array}{l}\text { mixed: } \mathrm{ST}=35 \\
\mathrm{~B}=18\end{array}$ & $\begin{array}{l}\mathrm{ST}: \mathrm{LL}=10, \mathrm{UL}=5 \\
\text { trunk }=3 \\
\mathrm{~B}: \mathrm{LL}=18, \mathrm{UL}=10 \\
\text { trunk }=7\end{array}$ & 52 \\
\hline 20 & Switzerland & prospective & 83 & - & - & $\mathrm{B}$ & unclear & 72 \\
\hline 21 & Japan & prospective & 31 & $45.2(11-83)$ & $12 / 19$ & $\begin{array}{l}\text { mixed: } \mathrm{ST}=23, \\
\mathrm{~B}=10\end{array}$ & $\begin{array}{l}\mathrm{LL}=22, \mathrm{UL}=7 \\
\text { trunk }=4\end{array}$ & 33 \\
\hline 24 & India & retrospective & 22 & $22.2(8-66)$ & $14 / 8$ & $\mathrm{~B}$ & $\begin{array}{l}\mathrm{LL}=16, \mathrm{UL}=3, \\
\text { trunk }=2, \text { head }=1\end{array}$ & 22 \\
\hline 25 & USA & retrospective & 98 & - & - & $\mathrm{B}$ & unclear & 64 \\
\hline 26 & Japan & retrospective & 103 & $59.1 \pm 18.6$ & $53 / 50$ & mixed & unclear & 103 \\
\hline 9 & USA & retrospective & 100 & $54(9-89)$ & $58 / 42$ & ST & $\mathrm{UL}$ and $\mathrm{LL}=100$ & 54 \\
\hline
\end{tabular}

SUV as it was reported in these studies. The analysis showed a sensitivity of $89.8 \%$ (95\% CI: 81.1-94.7\%), specificity of $75.8 \%$ (95\% CI: $68.8-81.6 \%$ ), and AUC of $88.1 \%$. On the other hand, visual assessment was used in 4 studies, and showed a sensitivity of $93.2 \%$ and AUC of $94.8 \%$, while the specificity dropped to $40 \%$. When the data of studies that used PET/CT in combination were pooled, sensitivity and specificity slightly increased to $89.2 \%(95 \%$ CI: 83.6-93.1\%) and 76.3\% (95\% CI: 70.4-82.7\%) compared to $82.3 \%$ (95\% CI: $76.8-90.3 \%$ ) and $73.9 \%$ (95\% CI: 66.8-80.0\%) in FDG-PET alone, respectively.

Seventeen studies provided data concerning SUV. Overall, benign bone and soft tissue tumors had an average SUV of $2.52(\mathrm{SD}=0.63)$, while malignant sarcomas 
Table 2. QUADAS-2 assessment of the 21 included studies in the meta-analysis assessing the risk of bias and applicability

\begin{tabular}{|c|c|c|c|c|c|c|c|}
\hline \multirow{2}{*}{$\begin{array}{l}\text { Ref. } \\
\text { No. }\end{array}$} & \multicolumn{4}{|c|}{ Risk of bias } & \multicolumn{3}{|c|}{ Applicability } \\
\hline & $\begin{array}{l}\text { patient } \\
\text { selection }\end{array}$ & $\begin{array}{l}\text { index } \\
\text { test }\end{array}$ & $\begin{array}{l}\text { reference } \\
\text { standard }\end{array}$ & $\begin{array}{l}\text { flow and } \\
\text { timing }\end{array}$ & $\begin{array}{l}\text { patient } \\
\text { selection }\end{array}$ & $\begin{array}{l}\text { index } \\
\text { test }\end{array}$ & $\begin{array}{l}\text { reference } \\
\text { standard }\end{array}$ \\
\hline 10 & low & unclear & unclear & low & low & unclear & low \\
\hline 11 & unclear & unclear & unclear & unclear & low & unclear & low \\
\hline 12 & low & high & unclear & low & high & unclear & low \\
\hline 13 & low & unclear & unclear & low & low & unclear & low \\
\hline 14 & low & unclear & unclear & unclear & low & low & low \\
\hline 15 & low & unclear & unclear & low & low & unclear & low \\
\hline 4 & low & unclear & unclear & low & low & unclear & low \\
\hline 16 & low & unclear & unclear & low & low & unclear & low \\
\hline 17 & low & unclear & unclear & high & low & unclear & high \\
\hline 18 & low & high & unclear & low & low & high & low \\
\hline 19 & low & high & unclear & unclear & low & unclear & low \\
\hline 20 & low & high & unclear & unclear & unclear & unclear & low \\
\hline 21 & unclear & unclear & unclear & low & unclear & unclear & low \\
\hline 3 & unclear & unclear & unclear & low & unclear & unclear & low \\
\hline 8 & low & low & unclear & unclear & low & unclear & low \\
\hline 22 & unclear & unclear & unclear & high & unclear & unclear & unclear \\
\hline 23 & low & high & unclear & low & low & unclear & low \\
\hline 24 & unclear & high & low & low & low & unclear & low \\
\hline 25 & unclear & unclear & unclear & low & high & high & low \\
\hline 26 & low & unclear & unclear & low & low & unclear & low \\
\hline 9 & high & high & unclear & high & high & low & unclear \\
\hline
\end{tabular}

had a mean of $6.81(\mathrm{SD}=1.03)$. These differences are statistically significant $(p<0.05)$. The range of SUVs was 0.83-11.4 for malignant and 0.63-5.1 for benign cases. Likewise, it was $0.83-1.3$ for low-grade sarcomas and 4.511.4 when they were of high grade. When pooling the accuracy measure of the high-quality studies with low risk of bias, sensitivity, specificity, and AUC were $88.5 \%$ (95\% CI 75.6-95.1\%), 65.6\% (95\% CI 47.1-80.3\%), and 88.2\%, respectively. Hunter's funnel plots showed no evidence to suggest any serious publication bias.

\section{Discussion}

The gold standard of diagnosis and grading of bone and soft tissue sarcomas is the histopathological examination of the tumor through biopsy, usually guided by anatomical imaging. Biopsy has a diagnostic accuracy of approximately $80 \%$ with a need of a redo-biopsy in $15-20 \%$ of cases, and a risk of complications estimated to be $20 \%$, of which $8 \%$ carry serious morbidities [13]. Radiographic tests such as X-ray, CT, and MRI are widely used for the diagnosis of musculoskeletal system malignancies. De-

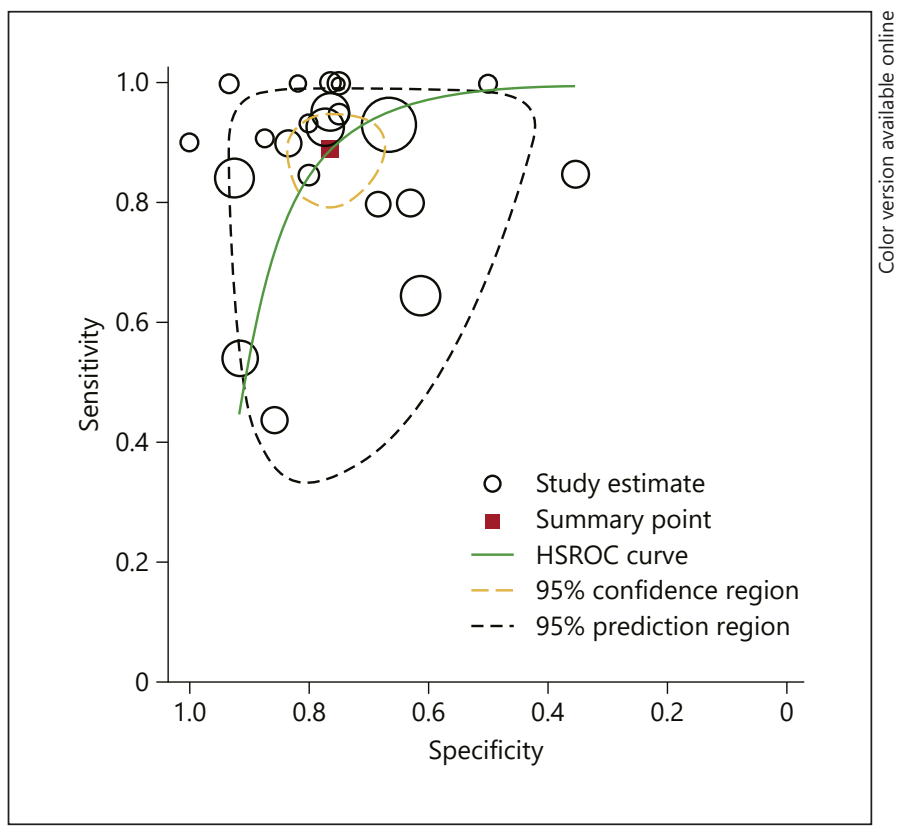

Fig. 2. Sensitivity and specificity for the detection of sarcoma. HSROC, hierarchical summary receiver-operating characteristic. 


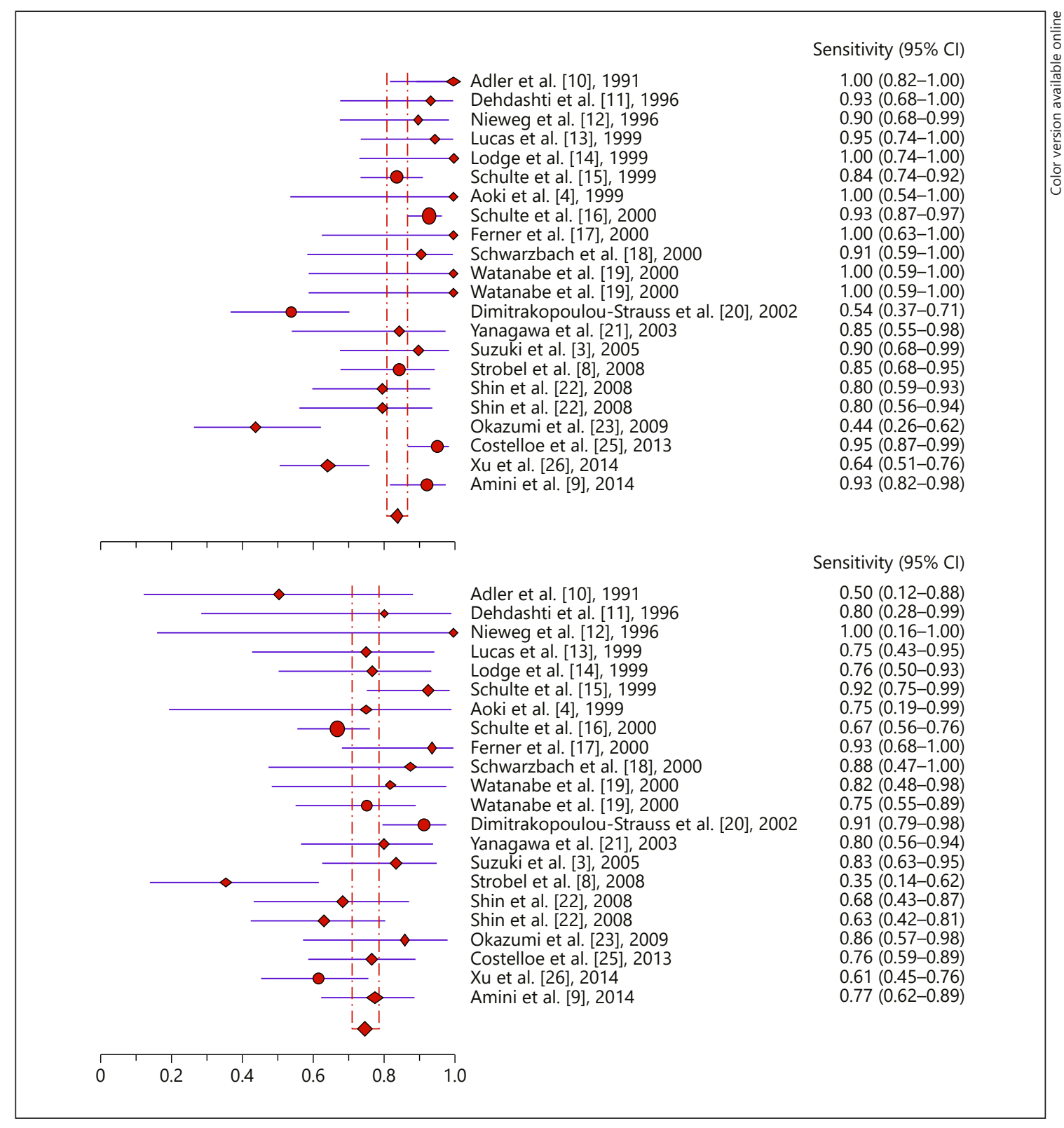

Fig. 3. Forest plot of the studies included.

spite the good anatomical localization and resolution for these tests, the ability of these methods to define the nature of musculoskeletal sarcomas was unsatisfactory raising the need for a different method for radiological assessment that addresses the histopathological grade of the sarcoma and helps guide treatment. FDG-PET is utilized for the quantification of glucose consumption of cells in the body, which makes it possible to measure the metabolic activity of malignant cells. However, because PET does not provide an accurate resolution of images, the combination of PET with CT has been long appreciated for providing detailed assessment of functional anatomy [22].

Our meta analyses indicated that FDG-PET is an efficient tool in the assessment of sarcomas with high sensitivity and specificity. We found FDG-PET could be an optimal screening tool for sarcoma to be ruled out. This is further asserted by the statistically and clinically different mean SUV values in sarcomas and benign tumors. Regarding the ability to differentiate benign from malignant 
tumors and grading the malignant tumors, FDG-PET showed some promising results, especially among specific histological groups such as chondroid tumors [2]. However, we were unable to discern the differences between different grades of sarcomas due to heterogeneous pathophysiological changes in the sarcoma group. The reported studies reflect the present clinical practice and had many characteristics that render the analysis of data critical for several reasons, most important being the clinical heterogeneity introduced due to varying measurement methods of FDG uptake. Additionally, the acquisition time for the SUV activity varied between studies from 40 to $60 \mathrm{~min}$. This is important as evidence suggests that FDG uptake by high-grade tumors continues to increase until $4 \mathrm{~h}$ [14]. It was also noticed that most of the studies using the semiquantitative SUV method did not specify whether they used the mean or maximum SUV, which is important for daily clinical practice $[3,4,9,11-14,17-19,21-26]$. Moreover, the varying SUV cutoff points used made it difficult to define a test as positive. Furthermore, some studies did not clearly describe the pathological criteria used for diagnosis. It was unclear whether each patient had the index and reference tests interpreted independently to avoid verification bias. Heterogeneity of reported pathology was another challenge where some studies included both soft tissue and bone sarcomas without providing sufficient data to separate them for analyses.

Despite the above-mentioned limitations, sensitivity analysis of high-quality studies of lower risk of bias found that FDG-PET had comparable sensitivity (88.5\%); however, the specificity dropped to $65.6 \%$. This further supports the idea that FDG-PET can serve as a good screening tool for sarcomas, bearing in mind the high rate of false-positive results that need to be interpreted carefully.

Our findings are consistent with what has been published in the literature. For instance, in their meta-analy- sis, Ioannidis and Lau [27] studied different SUV levels and evaluated the diagnostic accuracy associated with the use of different thresholds: $>2.0$ and $>3.0$. In 2004, Bastiaannet et al. [28] pooled the available evidence on the use of PET in the detection of sarcomas. They found that the overall sensitivity and specificity were 91 and 85\%, respectively. Etchebehere et al. [1] performed a systematic review to compare the accuracy of FDG-PET versus combined FDG-PET in the diagnosis of soft tissue musculoskeletal sarcoma. They found that FDG-PET/CT is more specific and accurate than dedicated FDG-PET. On the other hand, dedicated FDG-PET was more sensitive in the diagnosis of soft tissue sarcomas. To elucidate the value of PET/CT, Muheremu et al. [29] pooled the data of 16 trials and concluded that PET combined with CT is a reliable imaging method to be applied in the diagnosis of osseous and soft tissue malignancies. New diagnostic modalities including PET-MRI combinations have been investigated. However, the precise role that PET/MRI will play remains to be determined.

\section{Conclusion}

This systematic review studying the value of FDG-PET showed that it is a sensitive tool in the detection of primary bone and soft tissue sarcomas and the differentiation between benign and high-grade tumors. Further high-quality studies with standardized FDG uptake measures with varying SUV cutoff values are warranted.

\section{Disclosure Statement}

The authors do not have any conflicts of interest to declare.

\section{References}

1 Etchebehere EC, Hobbs BP, Milton DR, Malawi O, Patel S, Benjamin RS, et al. Assessing the role of ${ }^{18} \mathrm{~F}$-FDG PET and ${ }^{18} \mathrm{~F}$-FDG PET/ $\mathrm{CT}$ in the diagnosis of soft tissue musculoskeletal malignancies: a systematic review and meta-analysis. Eur J Nucl Med Mol Imaging. 2016 May;43(5):860-70.

2 Subhawong TK, Winn A, Shemesh SS, Pretell-Mazzini J. F-18 FDG PET differentiation of benign from malignant chondroid neoplasms: a systematic review of the literature. Skeletal Radiol. 2017 Sep;46(9):1233-9.
3 Suzuki R, Watanabe H, Yanagawa T, Sato J, Shinozaki T, Suzuki H, et al. PET evaluation of fatty tumors in the extremity: possibility of using the standardized uptake value (SUV) to differentiate benign tumors from liposarcoma. Ann Nucl Med. 2005 Dec;19(8):661-70.

4 Aoki J, Watanabe H, Shinozaki T, Tokunaga M, Inoue T, Endo K. FDG-PET in differential diagnosis and grading of chondrosarcomas. J Comput Assist Tomogr. 1999 Jul-Aug;23(4): 603-8.
5 Moher D, Liberati A, Tetzlaff J, Altman DG PRISMA Group. Preferred reporting items for systematic reviews and meta-analyses: the PRISMA statement. Int J Surg. 2010;8(5): 336-41.

6 Stroup DF, Berlin JA, Morton SC, Olkin I, Williamson GD, Rennie D, et al. Meta-analysis of observational studies in epidemiology: a proposal for reporting. Meta-analysis Of Observational Studies in Epidemiology (MOOSE) group. JAMA. 2000 Apr;283(15): 2008-12. 
7 Whiting PF, Rutjes AW, Westwood ME, Mallett S, Deeks JJ, Reitsma JB, et al.; QUADAS-2 Group. QUADAS-2: a revised tool for the quality assessment of diagnostic accuracy studies. Ann Intern Med. 2011 Oct;155(8): 529-36.

8 Strobel K, Exner UE, Stumpe KD, Hany TF, Bode B, Mende K, et al. The additional value of CT images interpretation in the differential diagnosis of benign vs. malignant primary bone lesions with 18F-FDG-PET/CT. Eur J Nucl Med Mol Imaging. 2008 Nov;35(11): 2000-8.

9 Amini B, Madewell JE, Chuang HH, Haygood TM, Hobbs BP, Fox PS, et al. Differentiation of Benign Fluid Collections from Soft-Tissue Sarcomas on FDG-PET/CT. J Cancer. 2014 Mar;5(5):328-35.

10 Adler LP, Blair HF, Makley JT, Williams RP, Joyce MJ, Leisure G, et al. Noninvasive grading of musculoskeletal tumors using PET. J Nucl Med. 1991 Aug;32(8):1508-12.

11 Dehdashti F, Siegel BA, Griffeth LK, Fusselman MJ, Trask DD, McGuire AH, et al. Benign versus malignant intraosseous lesions: discrimination by means of PET with 2[F-18]fluoro-2-deoxy-D-glucose. Radiology. 1996 Jul;200(1):243-7.

12 Nieweg OE, Pruim J, van Ginkel RJ, Hoekstra HJ, Paans AM, Molenaar WM, et al. Fluorine18-fluorodeoxyglucose PET imaging of softtissue sarcoma. J Nucl Med. 1996 Feb;37(2): 257-61.

13 Lucas JD, O’Doherty MJ, Cronin BF, Marsden PK, Lodge MA, McKee PH, et al. Prospective evaluation of soft tissue masses and sarcomas using fluorodeoxyglucose positron emission tomography. Br J Surg>. 1999 Apr; 86(4):550-6.

14 Lodge MA, Lucas JD, Marsden PK, Cronin BF, O'Doherty MJ, Smith MA. A PET study of 18 FDG uptake in soft tissue masses. Eur J Nucl Med. 1999 Jan;26(1):22-30.
15 Schulte M, Brecht-Krauss D, Heymer B, Guhlmann A, Hartwig E, Sarkar MR, et al. Fluorodeoxyglucose positron emission tomography of soft tissue tumours: is a noninvasive determination of biological activity possible? Eur J Nucl Med. 1999 Jun;26(6): 599-605.

16 Schulte M, Brecht-Krauss D, Heymer B, Guhlmann A, Hartwig E, Sarkar MR, et al. Grading of tumors and tumorlike lesions of bone: evaluation by FDG PET. J Nucl Med. 2000 Oct;41(10):1695-701.

17 Ferner RE, Lucas JD, O’Doherty MJ, Hughes RA, Smith MA, Cronin BF, et al. Evaluation of (18)fluorodeoxyglucose positron emission tomography ((18)FDG PET) in the detection of malignant peripheral nerve sheath tumours arising from within plexiform neurofibromas in neurofibromatosis 1. J Neurol Neurosurg Psychiatry. 2000 Mar;68(3):353-7.

18 Schwarzbach MH, Dimitrakopoulou-Strauss A, Willeke F, Hinz U, Strauss LG, Zhang YM, et al. Clinical value of [18-F]] fluorodeoxyglucose positron emission tomography imaging in soft tissue sarcomas. Ann Surg. 2000 Mar; 231(3):380-6.

19 Watanabe H, Shinozaki T, Yanagawa T, Aoki $J$, Tokunaga $\mathrm{M}$, Inoue $\mathrm{T}$, et al. Glucose metabolic analysis of musculoskeletal tumours using 18fluorine-FDG PET as an aid to preoperative planning. J Bone Joint Surg Br. 2000 Jul;82(5):760-7.

20 Dimitrakopoulou-Strauss A, Strauss LG, Heichel T, Wu H, Burger C, Bernd L, et al. The role of quantitative (18)F-FDG PET studies for the differentiation of malignant and benign bone lesions. J Nucl Med. 2002 Apr; 43(4):510-8.

21 Yanagawa $\mathrm{T}$, Watanabe $\mathrm{H}$, Inoue $\mathrm{T}$, Ahmed AR, Tomiyoshi K, Shinozaki T, et al. Carbon-11 choline positron emission tomography in musculoskeletal tumors: comparison with fluorine-18 fluorodeoxyglucose positron emission tomography. J Comput Assist Tomogr. 2003 Mar-Apr;27(2):175-82.
22 Shin DS, Shon OJ, Han DS, Choi JH, Chun KA, Cho IH. The clinical efficacy of (18)FFDG-PET/CT in benign and malignant musculoskeletal tumors. Ann Nucl Med. 2008 Aug;22(7):603-9.

23 Okazumi S, Dimitrakopoulou-Strauss A, Schwarzbach MH, Strauss LG. Quantitative, dynamic 18F-FDG-PET for the evaluation of soft tissue sarcomas: relation to differential diagnosis, tumor grading and prediction of prognosis. Hell J Nucl Med. 2009 Sep-Dec; 12(3):223-8.

24 Bandopadhyaya GP, Gupta P, Singh A, Shukla J, Rastogi S, Kumar R, et al. 99m Tc-DMSA (V) in evaluation of osteosarcoma: comparative studies with 18F-FDG PET/CT in detection of primary and malignant lesions. ISRN Oncol. 2012;2012:371830.

25 Costelloe CM, Chuang HH, Chasen BA, Pan T, Fox PS, Bassett RL, et al. Bone windows for distinguishing malignant from benign primary bone tumors on FDG PET/CT. J Cancer. 2013 Aug;4(7):524-30.

26 Xu R, Kido S, Suga K, Hirano Y, Tachibana R, Muramatsu $\mathrm{K}$, et al. Texture analysis on (18)F-FDG PET/CT images to differentiate malignant and benign bone and soft-tissue lesions. Ann Nucl Med>. 2014 Nov;28(9):92635.

27 Ioannidis JP, Lau J. 18F-FDG PET for the diagnosis and grading of soft-tissue sarcoma: a meta-analysis. J Nucl Med. 2003 May;44(5): 717-24.

28 Bastiaannet E, Groen H, Jager PL, Cobben DC, van der Graaf WT, Vaalburg W, et al. The value of FDG-PET in the detection, grading and response to therapy of soft tissue and bone sarcomas; a systematic review and meta-analysis. Cancer Treat Rev. 2004 Feb;30(1):83-101.

29 Muheremu A, Ma J, Amudong A, Ma Y, Niyazi $\mathrm{M}, \mathrm{Ou} \mathrm{Y}$, et al. Positron emission tomography/computed tomography for osseous and soft tissue sarcomas: A systematic review of the literature and meta-analysis. Mol Clin Oncol. 2017 Sep;7(3):461-7. 